\title{
Article title: Digitizing and contextualizing Australian audio-visual content: Australianscreen online (aso.gov.au)
}

\section{Contributor details:}

Ms Karina Aveyard

School of Humanities

Griffith University, Nathan Campus

170 Kessels Road

Nathan QLD 4111, Australia

Karina.Aveyard@griffithuni.edu.au

Karina Aveyard is a Ph.D. candidate at the School of Humanities at Griffith University. Her doctoral research examines contemporary cinema exhibition in regional and rural locations. This research is funded by an Australian Research Council Linkage Grant in partnership with the Australian government film agencies the National Film and Sound Archive and Screen Australia.

Ms Kate Stone

Manager NFSA online

National Film and Sound Archive

Level 1, 45 Murray Street

Pyrmont NSW 2009 Australia

Kate.Stone@nfsa.gov.au

Kate Stone is the NFSA's online Manager. She has worked on Australianscreen online from its inception as Project Manager, Editor and then Executive Producer. She has also written and directed award-winning short films and multimedia educational resources.

\section{Suggested citation:}

Aveyard, K. (2009), 'Vaultage: Digitizing and contextualizing Australian audio-visual content: Australianscreen online (aso.gov.au)', Studies in Australasian Cinema, 3.2, pp. 205-222, doi: 10.1386/sac.3.2.205/1. 


\section{Introduction}

Australianscreen online (http://aso.gov.au) is a web-based film archival resource that offers free access to an extensive range of historic Australian audio-visual material. The website is produced by the National Film and Sound Archive (NFSA). Audio-visual material is sourced from the NFSA's archives as well as those of its collection partners, the National Archives of Australia, public broadcasters ABC and SBS, and the Australian Institute of Aboriginal and Torres Strait Islander Studies (AIATSIS). Through these partnerships Australianscreen online covers all the major audio-visual collections in Australia.

The Australianscreen online website was launched in July 2007, preceded by an intensive two-year development phase. A year later, in July 2008, the project was transferred from Screen Australia to the NFSA when the latter was reconstituted as a separate statutory authority. A new version of the website (version 2.0) was launched in November 2009, featuring redesigned pages, more content for each title, several new categories and new sections for news, discussions forums and interactive games.

The collection currently has almost 1400 titles covering a wide range of formats and genres from professional productions (feature films, television programs, shorts and advertisements), to factual programmes (documentaries, newsreels, corporate films and other historical footage) and noncommercial content (home movies). The website also has a separate section that draws together indigenous content from the general format categories and profiles of Australian film-makers in its 'People' section.

Information available for each of the audio-visual titles in the collection includes a list of the main credits and other production information, synopsis, curator's notes, film-maker comments and up to three three-minute clips from the original material. In some cases, such as with the advertisements and newsreels, items can be viewed in their entirety directly from the website. For other titles there are links to information about how to access a copy of the complete film. The title listings are accompanied by education statements produced by the NFSA's education partner, Curriculum Corporation (through the Le@rning Federation, which coordinates/manages the online national resource pool and infrastructure of digital curriculum resources), aimed at the upper primary to mid-secondary education sector, which comprises around a third of the visitors to the site.

The website also has some new sections, launched in conjunction with version 2.0, which encourage users to visit the site more regularly and to explore and interact with the material. The three major new areas of the site comprise 'News', which provides information about new content and features on the site and other relevant news items; 'Groups', which provides a forum for online discussions and sharing of Australianscreen online content; and 'Games' designed to encourage exploration of the site’s content.

The website is targeted at a diverse audience including primary and secondary school children, tertiary researchers and students, screen industry practitioners, screen organizations and the general public. The 
site receives around 90,000 visits per month, of which around 25 per cent come from outside Australia. Around a third (30 per cent) of the visits are from the education sector.

Australianscreen online was recently recognized at the ATOM awards and the AIMIA awards, and received a Silver award at the International Academy of Visual Arts $\mathrm{W}^{3}$ awards, which honour creative excellence on the web.

The following interview with Kate Stone, Manager NFSA online, was prepared by Karina Aveyard.

KA: In recent years archives have placed increased emphasis on "access" as an integral part of their heritage responsibilities. Traditionally, however, archives have favoured collection philosophies that focus on the preservation and presentation of media in their original format. Whilst ASO enhances the accessibility and interactivity of the NFSA's audio-visual collection, it does this using a media for which most of its content was not originally intended. Is this an issue of any consequence for ASO especially now that it is housed at NFSA - what alterations are made to original materials in order for them to be presented effectively online for example?

KS: ASO was transferred to the NFSA at the time when the organization was re-established as a Statutory Authority and was given a clear mandate by government to increase the accessibility of its collection. ASO has received strong support at the NFSA, where there is an appreciation of what the site can contribute to its access agenda.

In some respects, the initiation of the project outside the archival environment (at the Australian Film Commission, now Screen Australia), meant ASO was not unduly burdened with concerns about format fidelity. Also, since that time there has been the huge growth in the number of movie and broadcaster websites streaming whole film and television titles. Not to mention the extraordinary numbers of young people apparently watcing movies on their mobile phones. These kinds of viewing practices have completely changed concepts of purity around the cinema experience since we began developing the website in 2005. Martin Scorsese, for example, who for many years resisted releasing his films on video, now supports a website that streams whole films. As he says, on 'The Auteurs' site:

I am proud to present this first line-up of films restored with the aid of the World Cinema Foundation. We launched the foundation in 2007 with the goal of restoring and preserving neglected films from around the world. We also understood, very quickly, that we needed to help create awareness of the films, to get them known and seen. That's why we entered into a partnership with The Auteurs. (Scorsese 2009) 
ASO goes to considerable effort to represent work in a way that is true to its original form. We digitize clips only from source material that is in the correct aspect ratio and has acceptable sound and image quality. We ask curators to describe when and where the work was originally seen, the intended audience and the response it received. ASO also edits an 'ident' to the beginning and end of audio-visual clips providing provenance metadata.

Having said that, ASO, despite having a small number of complete titles online (mostly advertisements), provides information and insight through representative samples rather than full screening experiences. And it constitutes only one form of access. The NFSA provides many opportunities for audiences to see films in their original cinematic contexts through public screenings run at its Arc cinema in Canberra and the touring programs, Big Screen, Black Screen and School Screen, which travel nationally. ASO also promotes opportunities to view Australian films on the big screen through its home page 'In Cinemas Now' feature.

In practical terms, to present films online the image and sound need to be compressed and this does affect quality. We have carefully managed the achievement of technical and quality standards with meeting the demands of accessibility. When work on the site commenced in 2005, the vast majority of teachers and schools were on dial-up speeds. For this reason we worked very hard to clear additional rights that allowed material to be downloaded so teachers could put the clips on their servers in advance of a lesson. It also meant that we offered clips in three sizes dial-up, broadband and 'premium quality', the latter suitable for projection. The quality of some of the dial-up clips was not ideal, but presenting clips in this format at least allowed teachers to access them. We stopped digitizing the dial-up version about six months ago when our user statistics showed that less than 3 per cent of visitors were still on dial-up speed connections.

\section{KA: What effect will the inclusion of an increasing amount of 'born digital' content have for the site?}

KS: It will help considerably with costs, as it will negate the need to have material transferred from analogue to digital.

Curatorially it will be interesting for a number of reasons. Once a title no longer goes through the traditional release windows (cinema, DVD, pay, free-to-air television over twelve to eighteen months) and instead is seen simultaneously in many formats on many different platforms, how then do you discuss its 'original release' context? How do you measure its 'success'? Audience response is more difficult to measure when the audience is highly fragmented, both in terms of location and delivery platform. Web metrics as a tool to price the market value of content is still a long way from the definitive tool we have with television ratings and cinema box office. 


\section{KA: Can you outline the importance of web-based initiatives like ASO to ensuring continued public engagement with Australian screen heritage? How does ASO work in terms of the NFSA's other online offerings, and more broadly the offerings of other Australian media sites such as enhanceTV?}

KS: ASO provides an important way for people to engage with our screen heritage but also, more broadly, our social and cultural history. It provides a variety of ways of looking at our screen heritage - creating overviews by facilitating the viewing of films in chronological order, genre, format or tag. ASO also provides interpretation and information, and with version 2.0, it has the added capacity for users to share their responses: play games, comment on the blog, start a group discussion, or write their own review for any title on the website.

We are at the beginning of a redevelopment of NFSA's corporate website, which will create more spaces for NFSA staff to communicate with stakeholders, clients and audiences. There will also be more integration between the NFSA main site and ASO. For example, by making connections between the representation of a title on ASO and items in the preservation section of the NFSA site about its restoration, or its place in a public program screening or event.

With external organizations, if there are education resources available for a title on other websites such as enhance TV or Metro, we link to them on the ASO page for that title.

While ASO provides a curated representation of the NFSA and other audio-visual collections, we are also highly conscious of its importance as an online search tool. Hence we consider the findability of the metadata and its visibility to search engines, the quality of the user interface and the quality of the back-end metadata to be critical areas of the site's functionality. To that end, the NFSA is currently scoping a major redevelopment of its public-facing online collection database to integrate collection data with rich content available online such as on ASO. The aim is to provide NFSA clients with a single service websearch tool that will find and aggregate content from across all our data sources, from ASO content to the NFSA's collection catalogue. The new service will allow the NFSA's corporate site and ASO to interconnect to recommend content to clients across domains.

KA: The ASO site offers selected content from the much larger NFSA catalogue and its curation clearly involved a great deal of thought and work. What themes and concepts has the NFSA sought to emphasize about Australian filmography, the screen industry and/or Australian history via ASO?

KS: ASO draws not only on the NFSA collection but a diverse range of collections of content partners ABC, SBS, AIATSIS and the National Archives, as well as the production archives of many independent production houses such as CAAMA, Australian Children's Television Foundation, Crawfords, Grundys (now Fremantle Media), Beyond and Southern Star and the commercial broadcasters. 
We work closely with curators in selecting content for the site. For example, for the animation section we asked two animation specialists - a practitioner, Antoinette Starkiewicz, and an academic and author, Marian Quigley - to each nominate twenty animated films they felt would provide a representative sample of Australian animation work on the site. These titles were in addition to a number of other animated films that had already been curated by others working on historical footage, advertisements or children's television programs. We also identify content for the site by consulting internally with NFSA curators and our online branch does its own research. There is a good depth and breadth of knowledge of both screen history and the production sector in the NFSA's online team and we recruit staff for knowledge rather than technical specialization.

ASO aims to be representative across all its categories. If an important title is not on the website, it will be due to one of the following reasons: we are unable to get permission to use it, we are unable to find a copy to view or digitize, or we just haven't got to it yet. There can be up to 100 titles at any one time in the production system, curated but not yet published, still being edited or seeking approvals. In the past twelve months we have curated numerous new titles including animation, shorts, experimental films, feminist films, television comedy/satire, television cop shows and some classic television miniseries. To date about 30 per cent of these have reached completion and have been published.

During the early development phase of the site, the curatorial process was overtaken slightly by the obligations to meet the project's deliverables - which were to build the website and publish 1000 titles within three years. In order to meet the time frame we were given, we prioritized titles that we were able to clear with copyright owners and for which there were copies of the film that were good enough to digitize. Initially the ABC's clearance requirements meant we could only choose titles that were currently available for purchase through an ABC outlet. Unfortunately this did not provide the overview of classic ABC programs that many users might have expected. A large number of the ABC titles on the site are talking heads in studios (Backchat, At the Movies, Mediawatch, 7.30 Report) because they have fewer rights clearance issues.

There has been a slight shift in the curatorial remit of the website since moving to the NFSA last year. As a project of the Australia Film Commission (which is now Screen Australia), ASO had been primarily about representing the body of work of an industry. However, it is now able to represent an increasing amount of material produced outside the Australian film industry and, therefore, provide a slightly broader reflection of Australia's social and cultural history.

Ultimately, the site remains representative only of what has been produced rather than representative of society in any broader sense. There are of course users who wish that the diversity of Australian culture was better represented on the website, and certainly our education partner, the Curriculum Corporation, is always asking if we can give them more clips of certain curriculum relevant topics. But if it hasn’t been made, we can’t add it. 


\section{KA: Fostering a new generation of appreciative and screen literate audiences is a major focus of ASO. How important is the educational component of ASO and to what extent has this influenced the website design as well as the curation and organization of the content?}

KS: The education component is a very important aspect of the ASO initiative. ASO is well oriented to the needs of secondary students as a result of our partnership with Le@rning Federation (through Curriculum Corporation), who have been with us since the project was established in 2005. As a result of their input, the site was originally built so that it would work on the oldest, slowest operating systems, browsers, screens and Internet connections. It meant that when the site was first launched it had no fancy Flash animation or slick graphics and there was a lot of explanatory text ('click here to download the clip' instead of icons). The site was also tested comprehensively with teachers. Unlike many of us, teachers are not at a desk online all day and in 2005 there were very few computers in schools. Our aim was to ensure the site was an easy to use resource, which could quickly locate the content users were searching for. To achieve this we had to prioritize the information and drop the decorative and time-consuming narratives whereby information is 'revealed' through time-wasting Flash presentations.

The education notes, produced by Le@rning Federation, were written around the clips rather than the entire film or title. The clips that have notes (1000 of them do) are organized in the 'Education' section so as to be discoverable through specific curriculum categories. Users can of course also find the education notes by simply browsing titles on the site. Over the next year the curriculum categories will be updated to match the new national curriculum and metadata will be added so online searches around the new curriculum (by teachers) will find the ASO resources. The Le@rning Federation have also provided advice on useful subjects to be incorporated into the site and selected the clips that receive education notes by assessing them against a curriculum relevance matrix.

While quality education resources and usability are extremely important, they can also be serious and rather dry. In redeveloping ASO we added a 'Games' section that aims to encourage young people to see the website as a place where they can have a bit of fun. Children and teenagers commonly browse the Internet scanning for words like 'games' 'kids' or 'fun'. If they don't find it, they tend to move on. ASO's games offer opportunities for younger users to have fun with the material and their knowledge, and encourage people to explore the enormous amount of material that is on the site. There are several components to the games section of the site including a quiz, and the creative game 'Take 2', which asks users to reinterpret or retell part of the story of a film on the site. The games are a very recent addition and are really still in the beta testing phase. We look forward to seeing how they are used and getting some feedback that will enable us to further develop these areas. 


\section{KA: Could you describe the feedback you have received from ASO users such as film-makers (copyright holders) screen industry organizations, educational organizations, researchers, students and the public more generally? How are different stakeholders using the site?}

KS: Generally, we get really fantastic feedback. Some industry people would like to see full credits on the site. This would be something that would really complete the website as a database and we are actively seeking a way to achieve this. We hear a lot from producers who are using the site to research new projects, create pitches for funding, check locations and actors and crew (for example, someone’s camera work). ASO also educates film-makers about their own history, which helps to locate their work in some context.

A number of films have been picked up for festival screenings on the basis of their listing on the ASO site. We also receive a lot of queries from visitors enquiring as to where they can buy copies of films. The good news is this year a lot of the Australian feature film back catalogue has been issued on DVD by distributors such as Umbrella and Madman.

Education users are also very happy with ASO. Our direct liaison with this sector is limited but evaluations undertaken by the Le@rning Federation indicate there is a high level of satisfaction with the site.

\section{KA: How have new digital and web-based technologies both facilitated and been utilized on the ASO site? Have software or bandwidth considerations limited what has been done with the site to date?}

KS: Optimizing the site for performance and embracing best practice web standards for audience accessibility compliments the goal of creating high quality, engaging experiences rather than limiting the potential for innovation. The new content recommendation and aggregation tools built for the latest version of the site, ASO version 2.0, work with the data structure to ensure that content is transmitted efficiently and is available on as many operating platforms as possible.

We incorporated a number of important technological innovations into version 2.0, which were designed to enhance the user experience and help create a community on the site. For example, our new social media space, 'green room', provides users familiar with networking and personalization the tools to engage with others on our site. Registration is free and allows users to review and discuss content as well as keep a personal page of friends and a history of user activity on ASO.

In terms of the more technical aspects of the site, ASO uses web standards and semantic markup throughout to assist with accessibility, compatibility and search engine optimization. The backend is built using the innovative Django web framework, allowing for flexible, agile development and deeply linked navigation. Due to the large size of the site (it contains over 1300 screen titles), the publishing is designed to contain descriptive subject, temporal and spatial metadata. In 
addition, new tools have been in-built to give audiences improved access to the depth of content on the site. For example, the landing page for titles showcases the diversity and quantity of content on the site by utilizing the descriptive data to its full potential - there is quick access to the discovery of titles through a range of options including tags, alphabetical order, date, place, genre or by recent trends in user activity. These tools are designed for simplicity of use and to assist in the visualization of the relationships between different items on the site.

ASO version 2.0 has also improved the structural framework of the site through greater use of microformats. These interfaces provide lightweight, highly engaging interactive framework for users and make content transportable to offsite applications while keeping data semantically separate from decoration and display. The updated site also includes greater use of Javascriptbased tools built from the jQuery code library to ensure that the highly interactive features of the site are available on as many platforms as possible. The implementation of jQuery embraces a widely used web standard and has the advantage for most users of already being cached on their web browsers.

In designing the new features of the site we also continued to make provision for users who do not have high-speed broadband access, as is still the case for many Australians. We implemented loading efficiencies by incorporating features that would cache the site and compress data transmission to achieve fast-loading pages.

Version 2.0 of the site also features a new media player that allows content that is cleared for sharing in blogs and social media sharing sites to be embedded. The site does not auto-load large media for this purpose but instead provides users with slow connections the option of downloading smaller files optimized for dial-up access. Users can set their media player preferences to match their bandwidth speed and those who do not have Flash can download clips at the quality appropriate for their connection.

\section{KA: What are some of the key challenges and future developments for ASO that you see ahead?}

KS: User expectations have risen dramatically, in line with the rapid developments of web technologies in the past two years. Keeping up with this is an enormous challenge, although it does also make for an exciting time. Things are moving so quickly that a website people thought was amazing two years ago can become inadequate within twelve months! Financial limitations determine to some extent how we are able to keep pace with these developments.

Expectations on rights holders, in terms of how they allow their content to be used, have also risen dramatically. When ASO was first launched, the protocol was to allow password protected access only from within an education institution's Intranets. People now expect to be able to download whole films and then re-use them. This expectation in particular has increased since ASO became part of the NFSA and users have assumed that the Archive, a government-owned body, also owns much of its audio-visual collection, which is not the case. 
The key challenges for the future centre on further developing the accessibility, relevance and usability of the site. We hope to develop a range of new and improved features and functionality for the site that will include:

- Further development of the interactive areas of the site, such as the groups, forums and games areas.

- Construction of an extension of the site where regional cultural organizations and independent producers are able to self-publish their content on ASO via user upload and completing a 'curator' template.

- Implement a web application that would allow users on mobile devices to view archival materials related to their current location.

- Further develop the existing location maps to allow different 'views' of Australia via different content types - for example, a view that shows only Indigenous-produced titles on an Indigenous nations map.

- Increase the links to related material across multiple sites including ASO, on NFSA corporate site as well as on external sites (such as other cultural organizations, film-makers' websites, education websites and so on).

- Enhance the functionality of the 'customization' tools, whereby users can customize the view and information they get on ASO either through preferences, browser history or recommendations (similar to Amazon's 'If you liked this title, you might also like...').

\section{References}

Scorsese, M, 'Vanguard Restoration: The First Films of the World Cinema Foundation', The Auteurs, http://www.theauteurs.com/cinemas/11. Accessed 15 December 2009. 